\title{
Invisible Knowledge Network of International Marketing Studies: Theory and Evidence
}

\author{
Tang Ting Wang \\ Chang Jung Christian University \\ E-Mail: Tanting.Wang@msa.hinet.net \\ Yuan-Duen Lee \\ Chang Jung Christian University \\ E-Mail: ydlee@mail.cjcu.edu.tw \\ Yen-Der McLee \\ Chang Jung Christian University \\ E-Mail: Yender_Lee@mail.cjcu.edu.tw
}

\begin{abstract}
This paper aims to explore the theoretical essentials of knowledge production of international marketing studies, from a dataset of 584 journal articles. A computer-aided co-citation network analysis of 21,828 citations that have been meticulously voted by over than ten-thousands of authors traces the historical timeline of the development paths and paradigms shift of international marketing studies. Using network analysis, we mapped the co-citation network and analyzed the top authors from 1997 to 2006. This could function as a concise reading list for Ph.D. students and assist them by economically providing material that acts as a roadmap for preparation for exams and assists in research work. Further, it could guide students in deciding their future research streams.
\end{abstract}

Keywords: International Marketing, Network of Knowledge, Co-citation Analysis

\section{INTRODUCTION}

Albaum and Peterson (1984) provided the following definition of International Marketing (IM): "marketing activities relevant to products or services that directly or indirectly cross national borders" (p. 162). This definition offers the benefit of being succinct and highlights the distinction between international marketing and marketing 
in general; in other words, it highlights the cross-national nature of IM. This paper chronicles the results of IM research journals. From a database developed from the citations in two IM research journals over a ten-year period, 1997-2006, this paper reports the relative academic importance of articles (in terms of number of citations) in the two journals. Our study analyzes ten years of research in IM from the publications in IM research journals. This paper employs scientometrics to serve an epistemological purpose, i.e., examine the influence of scholars and disciplines on IM. This paper focuses on the following three objectives: (1) ascertain important papers and books in IM, (2) establish the disciplines to which these works belong, and (3) construct a roadmap for new Ph.D. students that indicates the publication channels, particularly provide a strong epistemological foundation for holistic improvement as well as comprehensive study and research in their streams. To address the first issue, we examine the relative contributions of authors to the field of IM. Second, we classify works to evaluate the disciplinary trends in IM. Finally, we provide a roadmap for new Ph.D. students to identify the most cited publication avenues in their disciplines.

In this article, instead of evaluative bibliometrics (Narin, 1976), we employ epistemological scientometrics (Etemad \& Lee, 2003) to perform the following tasks: (1) examine the influence of individuals on IM research, (2) determine the disciplines and journals that have most influenced IM research, and (3) identify specific articles that have most impacted IM research. A natural by-product of this analysis is an assessment of the impact of a variety of research journals on IM research. Further, the ranking of IM journals (Frank, 2000) is carried out with the purpose of making knowledge easily accessible. We propose an invisible network of knowledge (INK) model to expedite the progress of a new researcher from knowing nothing to knowing something. We collected citation data from every issue of the Journal of International Marketing (JIM) and International Marketing Review (IMR) between 1997 and 2006. A detailed analysis of the 21,828 citations contained in the 584 documents in the journals reported in this study traced the chronology of IM's development path and paradigms.

\section{THEORY OF THE INVISIBLE NETWORK OF KNOWLEDGE}

Knowledge is power, and knowledge itself is simply the output of a learning (or knowing) process, similar to how plans are the output of a planning process. It is a complex concept that, before it was presented, it is stored in the learner's mind and is unobservable to the eye of voters (Doyle, et al., 1996). Since people harbor their own 
views on knowledge, there can be a lack of clarity concerning specific actions to be taken in the quest for knowledge. Therefore, there is a need for a channel that helps people to visualize knowledge and develop and maintain a common visualization and representation (Price, 1965). Gibbons et al., (1994) hold that the terms of science and knowledge are often interchangeably used or combined to form scientific knowledge and the scientific knowledge is usually presented in journal articles, books, and monographs as mentioned above. These pieces of knowledge in a particular field are developed based on each other and connected with each other through citations and co-citations. These citations and co-citations form a knowledge network within which there are subsystems or clique networks connected with each other; and this knowledge network is also a part of a broader and more general system (Chandy \& William, 1994). From this network perspective, the knowledge network of any single discipline, such as IM, could be viewed as an offshoot of the interaction of its foundational domains, such as marketing strategy, cross-national market segments, internationalization strategy, consumer behaviors and standardized advertising, which are well-established subsystems of IM (i.e., different streams of IM studies). We believe that further development of the IM research can benefit from a network analysis, i.e., author citation and co-citation analysis, of the field. This analysis will help us to combine knowledge gained from previous studies and to explore the nature, potential uses, and evolution of the field over time.

Networks have long been used in engineering and science for managing complex systems where they commonly refer to systems (webs) of interlinked subsystems (or components), each of which is optimally designed to effectively perform a designated task. Each subsystem is highly specialized and generally draws on high quality (Jones, et al., 1996) of accumulated knowledge and IM. By the optimal interlinking of these subsystems, a considerably broader and more complex range of functions and capabilities than that of individual subsystems is realized. Theoretically, the system as a whole may not be truly optimal; however, it can be adequately effective and flexible to execute tasks significantly better than its individual parts.

In the knowledge creation world, network concept has also been used to identify the role of invisible colleges in knowledge acquisition, which can be traced back to Derek Price's $(1963 ; 1965)$ proposal. He opined that research networks (made up of linkages connecting researchers with each other) link scholars form invisible colleges working in a research area through such informal media of communication as telephone calls, conversations at professional meetings, and preprint distributions. Mullins (1972) also corroborated Price's view and stated that researchers are 
stimulated by relatively small groups of colleagues working on the same issues and building on each other's work. Francis and Peter (1993) proposed that invisible colleges can be beneficial to a researcher in the following aspects: (1) identifying colleagues working on the same or related areas, (2) acquiring the knowledge from peers and enquiring about relevant topics in person or through the literature, and (3) formulating answers to these questions and communicating views via professional media, such as journals. These journals (particularly famous or major journals in each discipline) function elegantly and smoothly in the academic world, just like the market system works in the economic world, which was described as an "invisible hand" by the father of economics, Adam Smith (1776/1976), to influence the locus of development and diffusion of knowledge in each academic field.

Based on the above understandings, Etemad and Lee (2003) first metaphored and analogized a knowledge network as an airline map, and defined the network in knowledge creation as an "interlinked" web of "knots and nodes" that is "loaded" with "concentration of resources" scattered over a landscape that constitutes the domain of that subject. Later on, Ma, Lee and colleagues (Ma, et al., 2007) created a new concept of "an invisible network of knowledge production in a discipline (an INK Model)", which will be used for this study. In addition to the advantages of the traditional concept of a knowledge network, the INK is a more comprehensive model developed by co-citation network analysis to represent the invisible college in a field. An INK of a field will help us to gain an initial understanding of the nature, potential uses, and the evolution of that field over time. It can be viewed as a repository of broad and complex sets of expertise, experience, and accumulated knowledge of various aspects; further, it has certain key nodes and is enhanced by many linkages, from which both internal and external members can draw. Therefore, an INK is formed after (1) "nodes and knots" become loaded with knowledge resources (i.e., articles, authors, or journals), (2) these "nodes and knots" develop ties and linkages among themselves through co-citations (Podolny, et al., 1996), and (3) these ties synergistically amalgamate their resources, which in turn results in strengthening, broadening, and deepening the functional capabilities of both the network and its members (the research field).

A given INK embodies both the knowledge content of its nodes and the inter-linkages among the nodes within its. It can be viewed as the organized and the de facto representation of the knowledge content of a field. Chandy and William (1994) maintain that any localized knowledge network (in this study, the authors replaced knowledge network with INK) is a part (or subsystem) of a broader and more 
general system. From this perspective, the INK-IM, as an example of an emerging discipline with established origins, and which can be viewed as an offshoot of the interaction of its foundational domains. In the current study, we will use the INK to develop a network portrait of IM field in order to reveal a comprehensive and objective understanding of the evolvement of this field.

\section{RESEARCH METHODOLOGY}

The objective of this study is to focus on 584 articles in all the issues of two journals in the field of IM between 1997 and 2006. Thus, as a knowledge system, IM is an integral part of the social sciences. To evaluate the impact of other disciplines on IM research, we can employ journal citation as a proxy. Further, to identify the individuals who have exerted the greatest influence on the development of this discipline, our database includes references to articles, books, monographs, working papers, and dissertations cited in JIM and IMR between 1997 and 2006. This period was chosen because it represented the most recent decade for which the authors could obtain complete data on all citations. To provide a historical timeline perspective on the evolution of IM as a discipline, the sampling period was divided into two half decades. First, all the 21,828 citation data items were manually collected, checked, subtotaled and classified according to authors and the year of completion and accurately compared accurately. Second, Citation analysis was tabulated for each the 584 source document using the Excel package (Etemad, 2004). After a series of operation, key nodes in the invisible knowledge network in IM research were identified and the structure developed. Finally, co-citation analysis is conducted to utilize the social network analysis and factor analysis (Pilkington \& Teichert, 2006). The result of co-citation which mapping the intellectual structure of IM research and to explore the invisible knowledge nodes that have contributed most to the studies of IM and their possible evolution patterns.

\section{Identification of Databases and Design of Search Processes}

IM builds its structure on its constituent disciplines. Most of these disciplines, as discussed previously, are well established and have their own publication media. In the scenario marked by an absence of well-established media in IM, the researchers in this field published their work in the publication organs of their own field and other fields, which posed some challenges for this research. Most IM-related developments advanced considerably beyond what was drawn from its constituent disciplines, with the integration and coordination of raw materials from different disciplines for the 
purposes of application and development. However, works on these developments had to be published in the media of the constituent fields. This phenomenon widened the field for search of raw materials in IM and rendered the identification of boundary conditions extremely difficult. We use a conservative approach by examining the Social Science Citation Index (SSCI) for IM-oriented raw materials to identify our initial source databases. The SSCI citations contain over 1,800 refereed journals. Therefore, the results reported in this study are not limited to any specific field or area, which confirm the true interdisciplinary nature and means of sustenance of this field.

With the identification of the potential databases containing IM-related raw materials, appropriate search procedures needed to be adopted. For example, JIM and IMR are arguably the most influential journals publishing papers on IM. The advantage of this type of search strategy using the journal title is the "guaranteed quality" of the published papers and the clear boundaries of the accepted methods and topics in the field as defined by the editorial policies of the journal. The data set comprises 584 articles published between 1997 and 2006 and totals to 21,828 bibliographical references. Table 1 provides the number of articles and reference published each year for the period under consideration and helps us accurately compare in order to represent highly cited contemporary IM studies. Through this information, we aimed to explore the knowledge theoretical essentials.

Table 1 Source Sampling Distribution of Articles and Citation Samples in JIM and IMR

\begin{tabular}{cccc}
\hline Year & $\begin{array}{c}\text { Subtotal number of } \\
\text { published articles }\end{array}$ & $\begin{array}{c}\text { Average number } \\
\text { of references per article }\end{array}$ & $\begin{array}{c}\text { Subtotal number } \\
\text { of cited references }\end{array}$ \\
\hline 1997 & 36 & 17.17 & 618 \\
\hline 1998 & 29 & 21.34 & 619 \\
\hline 1999 & $*$ & $*$ & $*$ \\
\hline 2000 & 132 & 25.33 & 3343 \\
\hline 2001 & 79 & 32.70 & 2583 \\
\hline 2002 & 58 & 36.53 & 2119 \\
\hline 2003 & 60 & 46.22 & 2773 \\
\hline 2004 & 60 & 45.55 & 2733 \\
\hline 2005 & 67 & 50.61 & 3391 \\
\hline
\end{tabular}

Note: * implies that no records were available in the Web of Science collection. 


\section{Data Set and Co-citations Analyses}

Citations are considered to be an authentic and reliable indicator of scientific communication (Small, 1978; Garfield, 1979) and a basis for the identification of "invisible colleges," i.e., research networks that refer to each other in their documents without being linked by formal organizational ties (Price, 1965; Crane, 1972; Lievrouw, 1989). Co-citation is frequency with which two documents or authors are cited together by more recent papers (Alger, 1996). The basic assumption behind co-citation is that documents that are frequently cited together by succeeding works are related in subject matter. The essential notion is that the more frequently the two publications are co-cited, the stronger is their linkage. In co-citation analysis, the data compiled are counts of the number of times two works-individual documents, authors' oeuvres, and/or journal titles-are jointly cited in later publications (McCain, 1991). Therefore, co-citation analysis has been considered an efficient method to measure relationships and linkages between authors, papers, and journals to describe mainstream, or at least the leading edge, in science (Tsay, et al., 2003).

\section{RESULTS}

The results list the highly cited authors, books and journal articles, and the academic journals in the field of IM research. As mentioned above, we put IM studies into two difference periods: 1997-2001 and 2002-06. The results list the highly cited authors, books and journal articles, and the academic journals in the field of IM research. We will report our analysis results in the same fashion by presenting them in two different stages.

\section{Citation and co-citation frequency}

First of all, we analyzed all of the references and then selected the best cited 30 authors (the first author of articles) in the past 10 years (see Table 2 for the list; the years beside the scholars' names are the publication years of his/her representative and the mostly cited study). Second, we select the 30 most highly cited scholars in the two different periods 1997-2001 and 2002-06. Table 3 shows the top 30 main authors in two different stages according to the number of references found. We employ these scholars as key nodes before conducting a co-citation analysis. The results are given in Figures 1 and 2. 
Table 2 Historical Timeline of International Marketing

\begin{tabular}{cccl}
\hline Timeline & Citations & Type & \multicolumn{1}{c}{ Top Citation Index For Books And Articles } \\
\hline 1975 & 40 & B & Williamson OE-Markets hierarchies \\
\hline 1977 & 40 & J & Armstrong JS-Estimating non-response bias in mail surveys-JMR \\
\hline 1977 & 67 & J & $\begin{array}{l}\text { Bilkey WJ-The export behavior of smaller-sized Wisconsin } \\
\text { manufacturing firms-JIBS }\end{array}$ \\
\hline 1977 & 157 & J & Johanson J-The Internationalisation process of the firm-JIBS \\
\hline 1978 & 43 & B & Nunnally JC-Psychometric theory \\
\hline 1980 & 70 & B & Porter ME-Competitive strategy \\
\hline 1980 & 136 & B & Hofstede G-Cultures consequences \\
\hline 1982 & 44 & J & $\begin{array}{l}\text { Deshpande R-Factors affecting the use of marketing research } \\
\text { information-JMR }\end{array}$ \\
\hline 1983 & 53 & J & Levitt T-The globalization of markets-HBR \\
\hline 1983 & 86 & B & Douglas SP-International marketing research \\
\hline 1986 & 62 & J & Anderson E-Modes of foreign entry-JIBS \\
\hline 1988 & 50 & J & $\begin{array}{l}\text { Kogut B-The effect of national culture on the choice of entry } \\
\text { mode-JIBS }\end{array}$ \\
\hline 1988 & 70 & J & Anderson JC-Structural equation modeling in practice-PB \\
\hline 1989 & 38 & J & Jain SC-Standardization of International marketing strategy-JM \\
\hline 1992 & 69 & J & $\begin{array}{l}\text { Samiee S-The influence of global marketing standardization on } \\
\text { performance-JM }\end{array}$ \\
\hline 1993 & 44 & J & Erramilli MK-Service firms' international entry-mode choice-JM \\
\hline 1994 & 175 & J & Cavusgil ST-Marketing strategy-performance relationship-JM \\
\hline 1996 & 64 & J & Leonidou LC-The export development process-JIBS \\
\hline 1998 & 38 & B & Kotabe M-Global marketing management \\
\hline 1998 & 41 & J & $\begin{array}{l}\text { Steenkamp JBEM-Assessing measurement invariance in } \\
\text { cross-national consumer research-JCR }\end{array}$ \\
\hline 1998 & 51 & J & Zou S-The determinants of export performance-IMR \\
\hline & & &
\end{tabular}

According to the results of Table 2, the INK of IM in a given time period emerges as clear as twinkling stars in the cloudy sky of knowledge that symbolizes the historical timeline. Influential authors appeared in the last 10 years. The 21 most highly cited teams of authors (denoted by only the first author) along with their representative works are shown in Table 2. In the total sample of citations in the field of IM, the top 10 authors are S.T. Cavusgil, J. Johanson, G. Hofstede, S.P. Douglas, J.C. Anderson, M.E. Porter, S. Samiee, W.J. Bilkey, L.C. Leonidou, and E. Anderson 
Table 3 Top 30 Scholars Selected for the Co-citation Analysis

From 1997 to 2001 (Citation Frequency $\geqq 11$ )

\begin{tabular}{|c|c|c|c|c|c|c|}
\hline Cavusgil ST & 80 & Samiee S & 26 Alexander $\mathrm{N}$ & 16 Bollen KA & 14 Madsen TK & 12 \\
\hline Johanson J & 57 & Anderson JC & 23 Jain SC & 16 Buzzell RD & 13 Nunnally JC & 12 \\
\hline Douglas SP & 35 & Levitt T & 21 Armstrong JS & 15 Day GS & 13 Sternquist B & 12 \\
\hline Porter ME & 32 & Johansson JK & 19 Churchill GA & 15 Williamson OE & 13 Treadgold A & 12 \\
\hline Bilk & 31 & Welc & 18 Aaby NE & $14 \mathrm{Be}$ & $12 \mathrm{~B}$ & 11 \\
\hline Hofs & 30 & Anderson E & 17 Bagozzi RP & 14 Bentler PM & 12 Erra & 11 \\
\hline \multicolumn{7}{|c|}{ From 2002 to $2006 \quad$ (Citation Frequency $\geqq 23$ ) } \\
\hline Johanson J & 94 & Anderson E & 41 Deshpande R & 31 Jaworski BJ & 26 Katsikeas CS & 24 \\
\hline Hofstede G & 91 & Samiee S & 36 Porter ME & 28 Moorman C & 26 Malhotra NK & 24 \\
\hline Cavusgil ST & 81 & Steenkamp JEM & 34 Erramilli MK & 27 Parasuraman A & 26 Kohli AK & 23 \\
\hline Anderson JC & 47 & Bilkey WJ & 33 Knight GA & 27 Arms & 25 Mor & 23 \\
\hline $\begin{array}{l}\text { Leonidou } \\
\text { LC }\end{array}$ & 43 & Kogut B & 33 Nunnally JC & 27 Barney J & 24 Oviatt BM & 23 \\
\hline Douglas SP & 42 & Levitt T & 32 Bagozzi RP & 26 Hair JF & 24 Williamson OE & 23 \\
\hline
\end{tabular}

\section{Factor Analysis of Authors}

Following the example of previous studies (White, 1981; Culnan, 1986; Rowlands, 1999; Acedo, 2005), we considered that a work should be included in a particular research trend when its loading is equal to or greater than 0.4 , and if the loading is greater than 0.7 , the work is a contribution of great relevance within the corresponding paradigm. Tables 4 and 5 show the results of this analysis. Significantly, most of the authors' works are loaded with a weight greater than 0.7 , corroborating the relevance of these works within their respective paradigms. These works are of even greater interest, as they represent bridges between paradigms and allow us to observe a broader spectrum of influences among those works that belong to different research fronts, helping us to understand their evolution and the links that have been forming between the different research trends.

Based on the results of factor analysis shown in Table 4, we identified five groups, although some of them have a close mutual relationship. We made no attempts to interpret the remaining factors on account of their relative small eigenvalues $(\lambda>1)$. The first group is related to the study of "International Consumer Behavior and the Structural Equation Model," where we can include the works of Hofstede, Nunnally, Bagozzi, etc. Groups 2 and 3 represent the "Internationalization Process Model and IJVs." Group 2 includes the works most closely related to the "Internationalization Process Model" (Johanson, Bilkey, Cavusgil, etc.), while group 
3 focuses more on "Internationalization of Retailing" (Treadgold, Burt, Alexander, and Sternquist). Group 4 corresponds to the school we might call "Globalization and Cross-Cultural Research" (Douglas, Levitt, Samiee, etc.). Group 5 includes the works of Williamson, Anderson, and Erramilli, which reflect aspects pertaining to "Transaction Cost Theory and the Resources Capabilities Approach." As can be observed, all of the information is summarized in five factors that explain $85.2 \%$ of the variance. Significantly, most of authors are loaded with a weight greater 0.7 , corroborating the relevance of these works within their respective paradigms.

Table 4 Author Factor Loadings at 0.40 or Higher from 1997 to 2001

\begin{tabular}{|c|c|c|c|c|c|c|c|c|c|}
\hline \multicolumn{2}{|c|}{$\begin{array}{c}\text { Factor } 1 \\
\text { International } \\
\text { Consumer Behavior } \\
\text { and Structural } \\
\text { Equation Model }\end{array}$} & \multicolumn{2}{|c|}{$\begin{array}{c}\text { Factor } 2 \\
\text { Internationalization } \\
\text { Process Model and } \\
\text { IJVs }\end{array}$} & \multicolumn{2}{|c|}{$\begin{array}{c}\text { Factor } 3 \\
\text { Internationalization } \\
\text { of Retailing }\end{array}$} & \multicolumn{2}{|c|}{$\begin{array}{c}\text { Factor } 4 \\
\text { Globalization and } \\
\text { Cross-Cultural } \\
\text { Research }\end{array}$} & \multicolumn{2}{|c|}{$\begin{array}{c}\text { Factor } 5 \\
\text { Transaction Cost } \\
\text { Theory/ Resources } \\
\text { and Capabilities } \\
\text { Approach }\end{array}$} \\
\hline Bollen KA & .94 & Aaby NE & .93 & Treadgold A & .96 & Jain SC & .93 & Anderson E & .76 \\
\hline Bagozzi RP & .91 & Madsen TK & .84 & Burt SL & .96 & Levitt T & .91 & $\begin{array}{l}\text { Williamson } \\
\text { OE }\end{array}$ & .75 \\
\hline $\begin{array}{c}\text { Churchill } \\
\text { GA }\end{array}$ & .85 & Bilkey WJ & .81 & $\begin{array}{c}\text { Alexander } \\
\mathrm{N} \\
\end{array}$ & .95 & Buzzell RD & .88 & Erramilli MK & .71 \\
\hline Bentler PM & .85 & $\begin{array}{c}\text { Beamish } \\
\text { PW }\end{array}$ & .80 & Sternquist B & .95 & Porter ME & .81 & & \\
\hline Nunnally JC & .81 & Johanson J & .79 & & & Samiee S & .76 & & \\
\hline Hofstede G & .74 & Welch LS & .71 & & & Armstrong JS & .76 & & \\
\hline Day GS & .72 & Cavusgil ST & .70 & & & Douglas SP & .72 & & \\
\hline $\begin{array}{c}\text { Anderson } \\
\text { JC }\end{array}$ & .61 & & & & & Johansson JK & .57 & & \\
\hline Eigenvalues & 13.58 & & 5.57 & & 3.0 & & 2.37 & & 1.31 \\
\hline$\%$ Variance & 44.8 & & 18.4 & & 9.9 & & 7.8 & & 4.3 \\
\hline
\end{tabular}

Note: Extraction method, principal components analysis; rotation method, varimax

In another factor analysis presented in Table 5 as well, we identified five groups. We made no attempts to interpret the remaining factors on account of their relative small eigenvalues $(\lambda>1)$. Group 1 is related to the study of the "Internationalization Process Model and IJVs," where we can include the works of Johanson, Bilkey, Cavusgil, etc. Groups 2 and 3 represent "Globalization and Cross-Cultural Research." Group 2 includes the works most closely related to "Globalization and Cross-Cultural Research" (Douglas, Levitt, Samiee, etc.), while group three focuses more on "Market Orientation and Competitive Intensity" (Kohli, Jaworski, Deshpande, etc.). Group 4 corresponds to the school we might call "Transaction Cost Theory and the Resources 
Capabilities Approach" (Williamson, Anderson, Erramilli, etc.). Group 5 includes the works of Bagozzi, Anderson, and Morgan, which reflect aspects pertaining to "International Consumer Behavior and the Structural Equation Model." As can be observed, all of the information is summarized in five factors that explain $79.5 \%$ of the variance. Significantly, most of authors are loaded with a weight greater 0.7 , corroborating the relevance of these works within their respective paradigms.

Table 5 Author Factor Loadings at 0.40 or Higher from 2002 to 2006

\begin{tabular}{|c|c|c|c|c|c|c|c|c|}
\hline \multicolumn{2}{|c|}{$\begin{array}{c}\text { Factor } 1 \\
\text { InternationalizationPro } \\
\text { cess Model and IJVs }\end{array}$} & \multicolumn{2}{|c|}{$\begin{array}{c}\text { Factor } 2 \\
\text { Globalization and } \\
\text { Cross-Cultural } \\
\text { Research }\end{array}$} & \multicolumn{2}{|c|}{$\begin{array}{c}\text { Factor } 3 \\
\text { Market Orientation } \\
\text { and Competitive } \\
\text { Intensity }\end{array}$} & $\begin{array}{c}\text { Factor } 4 \\
\text { Globalization and } \\
\text { Cross-Cultural } \\
\text { Research }\end{array}$ & \multicolumn{2}{|c|}{$\begin{array}{c}\text { Factor } 5 \\
\text { International } \\
\text { Consumer Behavior } \\
\text { and Structural } \\
\text { Equation Model }\end{array}$} \\
\hline Bilkey WJ & .91 & Malhotra NK & .88 & 3 Kohli AK & .93 & Williamson OE & .87 Morgan RM & .77 \\
\hline Johanson J & .87 & $\begin{array}{l}\text { Steenkamp } \\
\text { JEM }\end{array}$ & & Jaworski BJ & .91 & Erramilli MK & .81 Anderson JC & .73 \\
\hline Knight GA & .85 & Levitt T & & Deshpande R & .89 & Kogut B & .79 Moorman C & .67 \\
\hline Oviatt BM & .85 & Parasuraman A & & 7 Nunnally JC & .63 & Anderson E & .76 Bagozzi RP & .63 \\
\hline Cavusgil ST & .83 & Douglas SP & .73 & & & Barney J & .67 Hair JF & .63 \\
\hline Katsikeas CS & .76 & Hofstede G & .72 & & & & & \\
\hline Leonidou LC & .75 & & & & & & & \\
\hline Samiee S & .69 & & & & & & & \\
\hline Porter ME & .65 & & & & & & & \\
\hline Armstrong JS & .62 & & & & & & & \\
\hline Eigenvalues & 10.63 & & 5.05 & & 3.95 & & 3.37 & 1.13 \\
\hline$\%$ Variance & 35.0 & & 16.6 & & 13.0 & & 11.1 & 3.7 \\
\hline
\end{tabular}

Note: Extraction method, principal components analysis; rotation method, varimax

\section{DISCUSSIONS}

We extract the following findings from Figure 1. In the INK between 1997 and 2001, Cavusgil is the most important scholar. Cavusgil and Zou (1994) acknowledge that organizational structure and processes should be derived from, and aligned with, a standardized marketing strategy. They developed a product technical complexity factor that comprised items such as strength of the patent, product intensity (i.e., a technological intensity-related element), amount of training required for salespeople and product service characteristics. According to the Uppsala internationalization model (Johanson \& Vahlne, 1977, 1990), knowledge of the market mainly comes from experience that is accumulated gradually. Thus, the internationalization process 
model can explain two patterns in the internationalization of a firm. The first pattern is that a firm's engagement in a specific country's market develops according to an establishment chain, and the second pattern is that a firm enters a new market with successively greater psychic distance (Johanson \& Vahlne, 1977). This view suggests that as a firm accumulates experience, resource commitment toward the foreign market increases.

\begin{tabular}{llllll}
\hline Co-citations & Line width & Pairs & Co-citations & Line width & Pairs \\
\hline $50+$ & $=$ & 0 & $21-30$ & - & 1 \\
\hline $41-50$ & $=$ & 0 & $15-20$ & - & 4 \\
\hline $31-40$ & $=$ & 0 & $0-14$ & $<$ blank $>$ \\
\hline
\end{tabular}

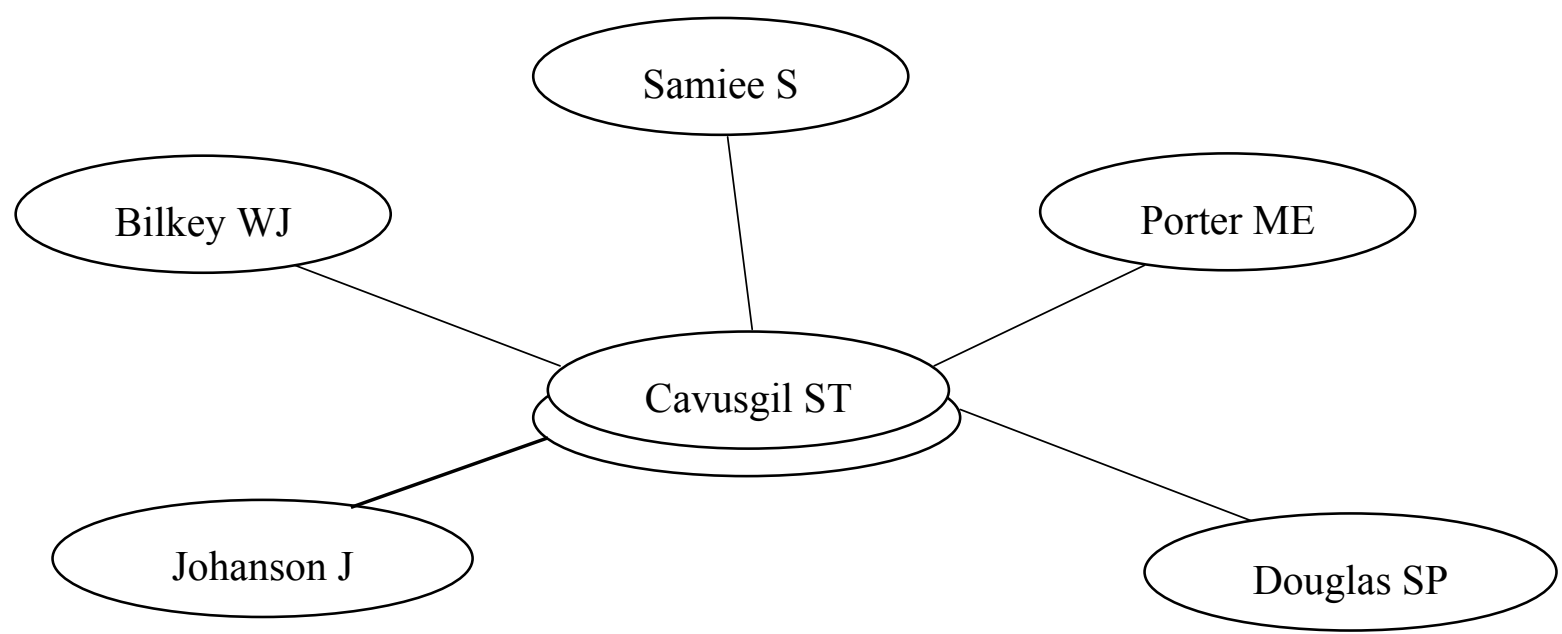

Figure 1 INK between 1997 and 2001

Douglas and Craig (1983) note that strategic decisions are likely to rely heavily on secondary data sources in addition to accumulated management experiences, while short-term tactical decisions are more likely to encourage the instrumental use of specific information and knowledge derived from primary data collection or research "tailored to the specific decisions to be made." Porter (1980) argued that a firm's success can be determined by the intensity of competition within the industry in which it operates in terms of the intensity of rivalry, supplier power, threats of new entrants and substitute products, and buyer power; these factors collectively produce and alter the nature of competitive intensity in the industry. It is argued that strategic decisions are affected by the collective competitive intensity of the five abovementioned 
competitive forces, as perceived by managers. Information and knowledge about foreign markets are also emphasized in the innovation-related models of internationalization. Incremental pattern of firm internationalization is a result of innovation adoption behavior (Bilkey \& Tesar, 1977).

We obtain the following findings from Figure 2. In the INK between 2002 and 2006, the main knowledge network has undergone change in a manner that indubitably validates concerning paradigm shifts (Kuhn, 1962, 1963). In this period, Hofstede, Leonidou, Katsikeas, Anderson, Steenkamp, Kogut, and Levitt were the emerging stars, and their studies changed the INK of IM. Marketing standardization, marketing strategies, export, IJVs, international consumer behavior, and the Uppsala internationalization model are still major competitive concepts that are applied in the field of IM. Hofstede (1980) proposed four dimensions to study cultural values: (1) power distance which explains the extent to which cultures accept social hierarchy and social inequalities, (2) uncertainty avoidance which measures cultures' tolerance for uncertainty and ambiguity in daily life, (3) masculinity/femininity which explores how gender roles are allocated in society, and (4) individualism/collectivism which explores individuals' relationships with society and the extent of societal-individual dependence. Together, these four cultural dimensions capture the essence of cultural values most commonly observable across cultures (Hofstede, 1980, 2001).

According to Leonidou and Katsikeas (1996), export remains the primary foreign market entry mode used by small businesses in their internationalization efforts. They highlight that existing models of the internationalization process tend to emphasize a forward progression from the pre-export stage to more commitment to international activity. Anderson and Gatignon (1986) proposed that international entry mode choices are a tradeoff between control and cost or resource commitments. They classified entry modes in terms of the amount of control the entering firm had over the foreign operation, and proposed that the efficiency of an entry mode depended on the subsequent transaction costs associated with the venture. Steenkamp and Baumgartner (1998) developed a systematic method to assess measurement invariance in cross-cultural marketing research. They propose a sequential procedure that is based on a factor analysis approach and a key assumption about the measure-construct validity of a small number of intercorrelated items that adequately tap the theoretical concept of interest. Kogut (1988) summarizes the advantages of cooperative alliances in terms of reducing the transaction costs resulting from small-number bargaining, enhancing the competitive position or market power of the partners, and acquiring organizational knowledge and learning. Additionally, Levitt (1983) indicated that 
customer preference could be enhanced through global recognition. Furthermore, customer similarity as an antecedent of marketing program standardization in both markets is a reflection of how the homogenization of markets is an important process underlying the feasibility of standardization.

\begin{tabular}{llllll}
\hline Co-citations & Line width & Pairs & Co-citations & Line width & Pairs \\
\hline $50+$ & $=$ & 0 & $21-30$ & - & 5 \\
\hline $41-50$ & $=$ & 0 & $15-20$ & & 28 \\
\hline $31-40$ & $=$ & $0-14$ & $<$ blank $>$ \\
\hline
\end{tabular}

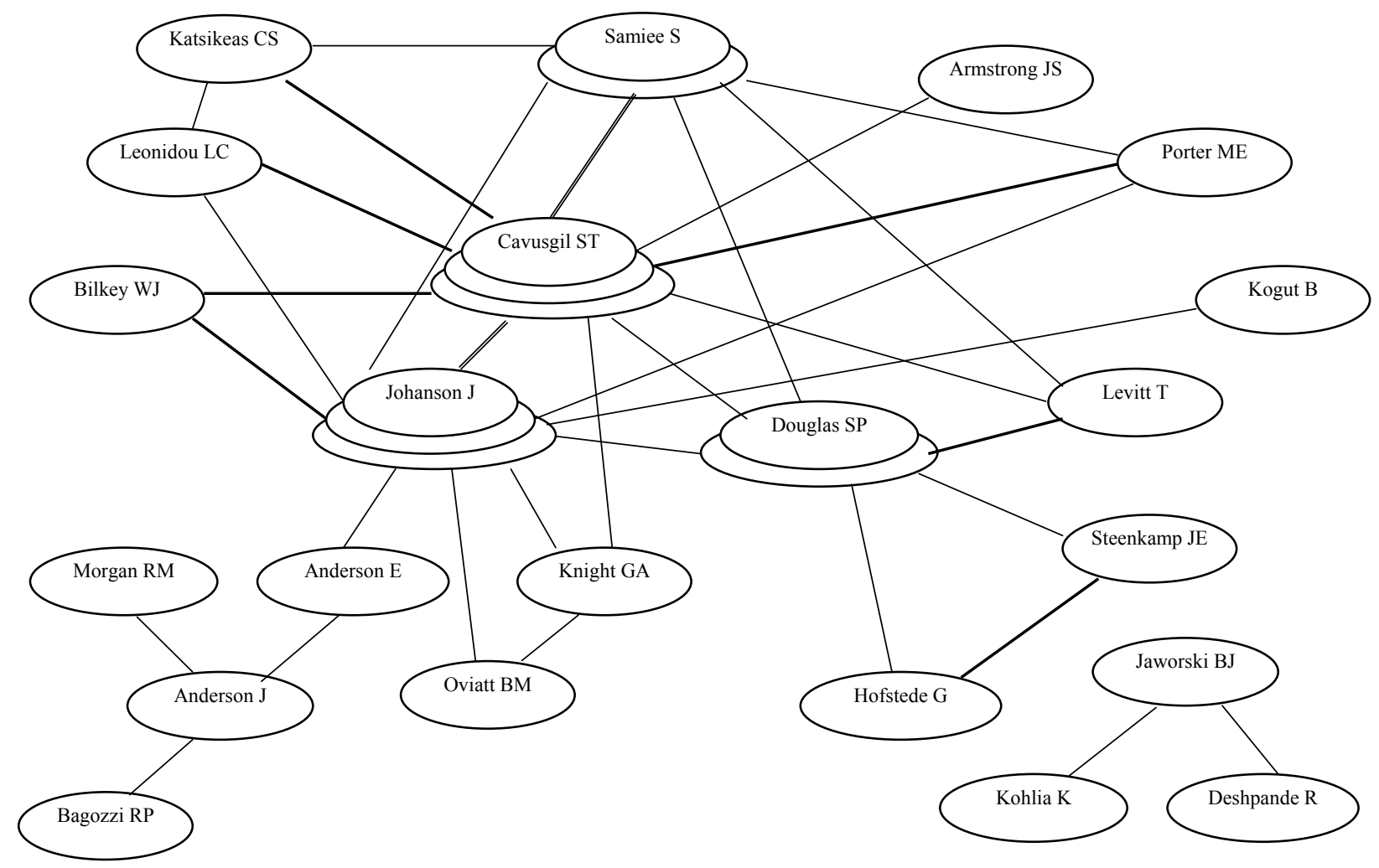

Figure 2 INK between 2002 and 2006

In another cluster in Figure 2, many scholars focus on the market orientation of research. For example, Jaworski and Kohli (1993) and Deshpande and Zaltman (1982) indicated that interdepartmental connectedness in the process of playing a facilitating role in creating a market orientation is likely to have a positive impact on firms' performance in sales, market share, profit, and return on investment, among other factors. Hence, the market information collected needs to be precise, carefully 
measured, controlled, and analyzed, and the results obtained should enable managers to reduce decision-making uncertainty (Deshpande \& Zaltman, 1982). In addition, Kohli and Jaworsky (1990) offered a behavioral definition of market orientation. They proposed that market orientation comprises three conceptual dimensions: "the organization-wide generation of intelligence pertaining to current and future customer needs, dissemination of intelligence across departments, and organization-wide responsiveness to it." Combining the perspectives of Jaworski and Kohli, conceptual and empirical research on the concept of market orientation has long suggested that interfunctional coordination is key to achieving the main goal of marketing - the creation of superior customer value (Jaworski \& Kohli, 1993; Kohli \& Jaworski, 1990). In response to researchers' calls for validity generalizations and cross-validations in structural equation modeling (SEM), the model estimation employs the minor product decision for validation (Bagozzi \& Yi, 1988). Additionally, Anderson and Gerbing (1988) provided a two-step approach with an initial measurement model and a subsequent structural model for SEM. Katsikeas et al., (2000) criticized the performance measures used in export studies as problematic in terms of difficulties in measuring, conceptualizing, and operationalizing the export performance construct. It is hoped that researchers will eventually produce a readily agreed upon set of performance indicators. Further, from a resource-based view, Oviatt and McDougall (1994) emphasized the importance of resource utilization, defined as the number of primary activities undertaken outside the home country.

\section{CONCLUSIONS}

The research in IM plays a significant role in the development of international business management literature and provides important guidelines for the multinational corporations (MNC). In order to understand the state of IM research and the linkages between IM studies, this paper provides a co-citation network analysis to map the evolving patterns of the IM field in ten-year. While there have been many review articles with different methodologies (literature review and meta-analytic review) as discussed previously. The contribution of this paper is to provide a valuable research direction in the IM and propose an objective and systematic mean of determining the relative importance of different knowledge nodes in the development of the IM field. Useful value added is offered by this study, not only because it is the first study to apply bibliometric techniques to IM research literature, but also because it complements and improves the findings of other studies that have approached the subject from the qualitiative perspective. 
This study constructs the INK of IM for the period between 1997 and 2006; in addition, it discusses the key nodes or most important scholars in this phase. These nodes and linkages provide considerable knowledge resources for Ph.D. students and new researchers who desire to independently study the disciplines related to IM. Specifically, this study identifies the most popular and highly cited journal articles, books, and researchers in the field of IM. The result derived from citations can provide the direction of research in IM. In addition, the so-called research procedures provided in the INK model can be applied to another field of research. Moreover, research can be identified through the "keyword intersection" approach, which uses keywords associated with salient concepts to search for related content across publication media and locations.

\section{REFERENCES}

Acedo, F. J., \& Casillas, J. C. (2005). Current paradigms in the international management field: An author co-citation analysis. International Business Review, 14(5), 619-639.

Albaum, G., \& Peterson, R. A. (1984). Empirical research in international marketing: 1976-1982. Journal of International Business Studies, 15(1), 161-173.

Alger, J. (1996). Can RANK be used to generate a reliable author list for co-citation studies? College \& Research Libraries, 57(6), 567-574.

Anderson, E., \& Gatignon, H. (1986). Modes of foreign entry: A transaction cost analysis and propositions. Journal of International Business Studies, 17(3), 1-26.

Anderson, J. C., \& Gerbing, D. W. (1988). Structural Equation Modeling in practice: A review and recommended two-step approach. Psychological Bulletin, 103(3), 411-423.

Bagozzi, R. P., \& Yi, Y. (1988). On the evaluation of Structural Equation Models. Journal of the Academy of Marketing Science, 16(1), 74-94.

Bilkey, W. J., \& Tesar, G. (1977). The export behavior of smaller-sized Wisconsin manufacturing firms. Journal of International Business Studies, 8(1), 93-98.

Cavusgil, S. T., \& Zou, S. (1994). Marketing strategy-performance relationship: An investigation of the empirical link in export market ventures. Journal of marketing, 58(1), 1-21.

Chandy, P. R., \& William, T. G. F. (1994). The impact of journals and authors on international business research: A citation analysis of JIBS articles. Journal of International Business Studies, 25(4), 715-728. 
Crane, D. (1972). Invisible colleges: Diffusion of knowledge in scientific communities. Chicago, IL, USA: University of Chicago Press.

Culnan, M. J. (1986). The intellectual development of management information systems, 1972-1982, a co-citation analysis. Management Science, 32(2), 156-172.

Deshpande, R., \& Zaltman, G. (1982). Factors affecting the use of marketing research information: A path analysis. Journal of Marketing Research, 19(1), 14-31.

Douglas, S. P., \& Craig C. S. (1983). International marketing research. Englewood Cliffs, NJ: Prentice Hall.

Doyle, J. R., Authurs A. J., McAulay, L., \& Osborne, P. G. (1996). Citation as effortful voting: A reply. Omega, 24(5), 603-606.

Etemad, H., \& Lee, Y. (2003). The knowledge network of international entrepreneurship: Theory and evidence. Small Business Economics, 20(1), 5-23.

Etemad, H. (2004). E-commerce: The emergence of a field and its knowledge network. International Journal of Technology Management, 28(7-8), 776-800.

Francis, W. W., \& Peter, M. S. (1993). Research administrators as "Invisible College" facilitators. SRA Journal, 24(4), 27-34.

Frank, L. D., \& David, M. R. (2000). Ranking the international business journals. Journal of International Business Studies, 31(4), 689-704.

Garfield, E. (1979). Is citation analysis a legitimate evaluation tool? Scientometrics, 1(4), 359-375.

Gibbons, M., Limoges, C., Nowwotny, H., Schwartzman, S., Scott, P., \& Trow, M. (1994). The new production of knowledge: The dynamics of science and research in contemporary societies. London: Sage.

Hofstede, G. (1980). Cultural consequences: International differences in work-related values. Bevery Hills: Sage Publication.

Hofstede, G. (2001). Culture's consequences: Comparing values, behaviors, institutions and organizations across nations. Thousand Oaks, CA: Sage Publications.

Jaworski, B. J., \& Kohli, A. K. (1993). Marketing orientation: Antecedents and consequences. Journal of Marketing, 57(3), 53-70.

Johanson, J., \& Vahlne, J. E. (1977). The internationalisation process of the firm: A model of knowledge development and increasing foreign market commitment. Journal of International Business Studies, 8(1), 23-32.

Johanson, J., \& Vahlne, J. E. (1990). The mechanism of internationalization. International Marketing Review, 7(4), 11-24. 
Jones, M. J., Binn, T., \& Pendlebury, M. (1996). Judging the quality of research in business schools: A comment from accounting. Omega, 24 (5), 597-602.

Katsikeas, C. S., Leonidou, L. C., \& Morgan, N. A. (2000). Firm-level export performance assessment: Review, evaluation, and development. Journal of the Academy of Marketing Science, 28(4), 493-511.

Kogut, B., \& Singh, H. (1988). The effect of national culture on the choice of entry mode. Journal of International Business Studies, 19(3), 411-432.

Kohli, A. K., \& Jaworski, B. J. (1990). Market orientation: The construct, research propositions, and managerial implications. Journal of marketing, 54(2), 1-18.

Kuhn, T. (1962). The structure of scientific revolutions. Chicago: University of Chicago Press.

Kuhn, T. (1963). The function of dogma in scientific research. New York: Basic Books in A. C. Crombie (ed.), Scientific Change.

Leonidou, L., \& Katsikeas, C. (1996). The export development process: An integrative review of empirical models. Journal of International Business Studies, 27(3), 517-551.

Levitt, T. (1983). The globalization of markets. Harvard Business Review, 61(May-June), 92-102.

Lievrouw, L. A. (1989). The invisible college re-considered. Communication Research, 16(5), 615-628.

Ma, Z., Lee, Y., Lee, Y., \& Yu, K. (2007). An invisible network of knowledge production: 10 years of human resources management studies. Proceedings of the annual meeting of the Administrative Sciences Association of Canada (ASAC), Ottawa, Ontario, 28(9), 82-97.

McCain, K. W. (1991). Mapping economics through the journal literature: An experiment in journal co-citation analysis. Journal of the American Society for Information Science, 42(4), 290-296.

Mullins, N. C. (1972). The development of a scientific specialty. Minerva, 10(1), 51-82.

Narin, F. (1976). Evaluative bibliometrics: The use of publication and citation analysis in the evaluation of scientific activity. Cherry Hill, N.J.: Computer Horizons.

Oviatt, B. M., \& McDougall, P. P. (1994). Toward a theory of new international ventures. Journal of International Business Studies, 25(1), 45-64.

Pilkington, A., \& Teichert, T. (2006). Management of technology: Themes, concepts and relationships. Technovation, 26(3), 288-299. 
Podolny, J. M., Stuart, T. E., \& Hannan, M. T. (1996). Networks, knowledge, and niches: Competition in the worldwide semiconductor industry, 1984-1991. American Journal of Sociology, 102(3), 659-689.

Porter, M. E. (1980). Competitive strategy. New York: Free Press.

Price, D. J. D. S. (1963). Little science, big science. New York: Columbia University Press.

Price, D. J. D. S. (1965). Networks of scientific papers. Science, 149(3683), 510-515.

Rowlands, I. (1999). Patterns of author co-citation in information policy: Evidence of social, collaborative and cognitive structure. Scientometrics, 44(3), 533-546.

Small, H. G. (1978). Cited documents as concept symbols. Social Studies of Science, 8(3), 327-340.

Smith, A. (1776/1976). An inquiry into the nature and causes of the wealth of nations. Oxford: Oxford University Press.

Steenkamp, J. E. M., \& Baumgartner, H. (1998). Assessing measurement invariance in cross-national consumer research. Journal of Consumer Research, 25(1), 78-90.

Tsay, M. Y., Xu, H., \& Wu, C. W. (2003). Author co-citation analysis of semiconductor literature. Scientometrics, 58(3), 529-545.

White, H. D., \& Griffith, B. C. (1981). Author co-citation: A literature measure of intellectual structure. Journal of the American Society for Information Science, 32(3), 163-172. 
